\title{
Evidence of past fluctuations on Stancomb-Wills Ice Tongue, Antarctica, preserved by relict flow stripes
}

\author{
J. WUITE, ${ }^{*}$ K.C. JEZEK \\ Byrd Polar Research Center, The Ohio State University, 1090 Cormack Road, Columbus, Ohio 43210-1002, USA \\ E-mail: jan.wuite@uni.lu
}

\begin{abstract}
This paper presents a newly derived velocity field of the Brunt Ice Shelf and Stancomb-Wills Ice Tongue in East Antarctica. Velocity is derived using automated feature-tracking techniques on RADARSAT-1 imagery from the 1997 Antarctic Mapping Mission-1 (AMM-1) and 2000 Modified Antarctic Mapping Mission (MAMM). We measure velocities up to $1350 \mathrm{~m} \mathrm{a}^{-1}$ at the ice front. Closer investigation of the velocity field and radar images reveals an obvious divergence of contemporary flowlines from relict flow stripes along a portion of Stancomb-Wills Ice Tongue. Analysis of relict flow stripes can reveal glacial events in the past. Assuming relatively steady flow since the event occurred, we utilize the current velocity field to reconstruct former stripe configuration. We believe the flowline deviation points to a change in dynamics that occurred approximately 140 years ago, perhaps due to thinning and an associated shift in grounding-line position. This seems to be supported by historic observations and bottom topography data.
\end{abstract}

\section{INTRODUCTION}

The break-up of several ice shelves in the Antarctic Peninsula has sparked concern among scientists about the stability and sensitivity of other larger ice shelves in Antarctica. Velocity measurements are necessary to find out whether they undergo, or are susceptible to, the same sudden changes as rapidly changing glaciers found elsewhere. Here we derive and investigate the velocity field of the Brunt Ice Shelf system, one of the larger ice shelves in Antarctica. The Brunt Ice Shelf system is situated on the Caird Coast on the western shore of the Weddell Sea. It is part of an almost continuous fringing ice shelf along the coast of Coats Land and Dronning Maud Land in East Antarctica. The Brunt Ice Shelf system consists of the Brunt Ice Shelf (BIS) and adjacent Stancomb-Wills Ice Tongue (SWIT). SWIT is a fast-moving ice tongue that is fed by Stancomb-Wills Glacier and extends more then $225 \mathrm{~km}$ beyond its grounding line. The width at the ice front is approximately $70 \mathrm{~km}$. SWIT is bordered on the east side by the Riiser-Larsen Ice Shelf and Lyddan Island, separated by a large rift system in places filled with sea ice. Rignot (2002) used interferometric synthetic aperture radar (InSAR) to investigate the velocity and mass budget of the glacier. He measured a flow velocity of $700 \mathrm{~m} \mathrm{a}^{-1}$ near the grounding line, accelerating to more than $1200 \mathrm{~m} \mathrm{a}^{-1}$ at the calving front. The estimated mass flux of $16.6 \pm 2 \mathrm{~km}^{3}$ ice $\mathrm{a}^{-1}$ gives the glacier a slightly positive mass balance of about $0.9 \mathrm{~km}^{3}$ ice $\mathrm{a}^{-1}$.

To the west SWIT is separated from the slower-moving BIS by a large shear zone consisting of a melange of large ice rafts and sea ice covered with snow. Hulbe and others (2005) estimated that $20-30 \%$ of the total ice shelf is marine ice. They tracked several large rafts over a time interval of about 2.5 years and found their relative position to be constant, implying that the icebergs and marine ice in which they are embedded move as one mechanically connected unit.

*Present address: Faculté des Sciences, de la Technologie et de la Communication, Université du Luxembourg, 6 rue Richard CoudenhoveKalergi, L-1359, Luxembourg, Luxembourg.
The BIS is bounded on the seaward side by an area known as the McDonald Ice Rumples, a zone of ice grounded on a number of pinning points. This ice shelf has received more scientific attention than SWIT since it houses the British Halley $\mathrm{V}$ station. Several studies have been conducted to measure movement of the current station and its predecessors. Older studies have been complicated because of an absence of fixed points in a wide radius around the station. Survey techniques included astro-fixes, repeated magnetic surveys, and mapping using grounded icebergs as control points (Thomas, 1973). Reported velocities range from 349 to $431 \mathrm{~m} \mathrm{a}^{-1}$ for the period up to 1972 (Ardus, 1965; Thomas, 1973; Simmons and Rouse, 1984). Simmons and Rouse (1984) reported a pronounced acceleration of the ice shelf starting in 1972, when the velocity of the station nearly doubled to $740 \mathrm{~m} \mathrm{a}^{-1}$. This velocity remained relatively constant until 1999, after which it has reportedly been decelerating at an average rate of about $40 \mathrm{ma}^{-1}$ (BAS, 2007).

\section{DATA AND METHODS}

With the launch of the RADARSAT-1 satellite and the subsequent RADARSAT-1 Antarctic Mapping Project (RAMP) a unique opportunity arose to derive ice-flow velocity of Antarctica's glaciers remotely. RAMP completed two mapping missions, the Antarctic Mapping Mission 1 (AMM-1) in 1997 and the Modified Antarctic Mapping Mission (MAMM) in 2000 (Jezek, 1998, 2002). The primary goals for the MAMM mission were to produce image mosaics of the coastal areas of Antarctica (north of $80^{\circ} \mathrm{S}$ ) for change detection and to measure surface velocity. We apply feature tracking on the $25 \mathrm{~m}$ RADARSAT- 1 imagery to derive 3 year averaged velocities for the BIS and SWIT for the time interval 1997-2000. Feature tracking is done automatically using IMCORR, an image cross-correlation method described by Bindschadler and Scambos (1991). IMCORR is used widely in the glaciological community to derive glacier velocity (e.g. Bindschadler and Scambos, 1991; Lucchita and others, 1993; Bindschadler and others, 1996; Berthier and others, 2003). 

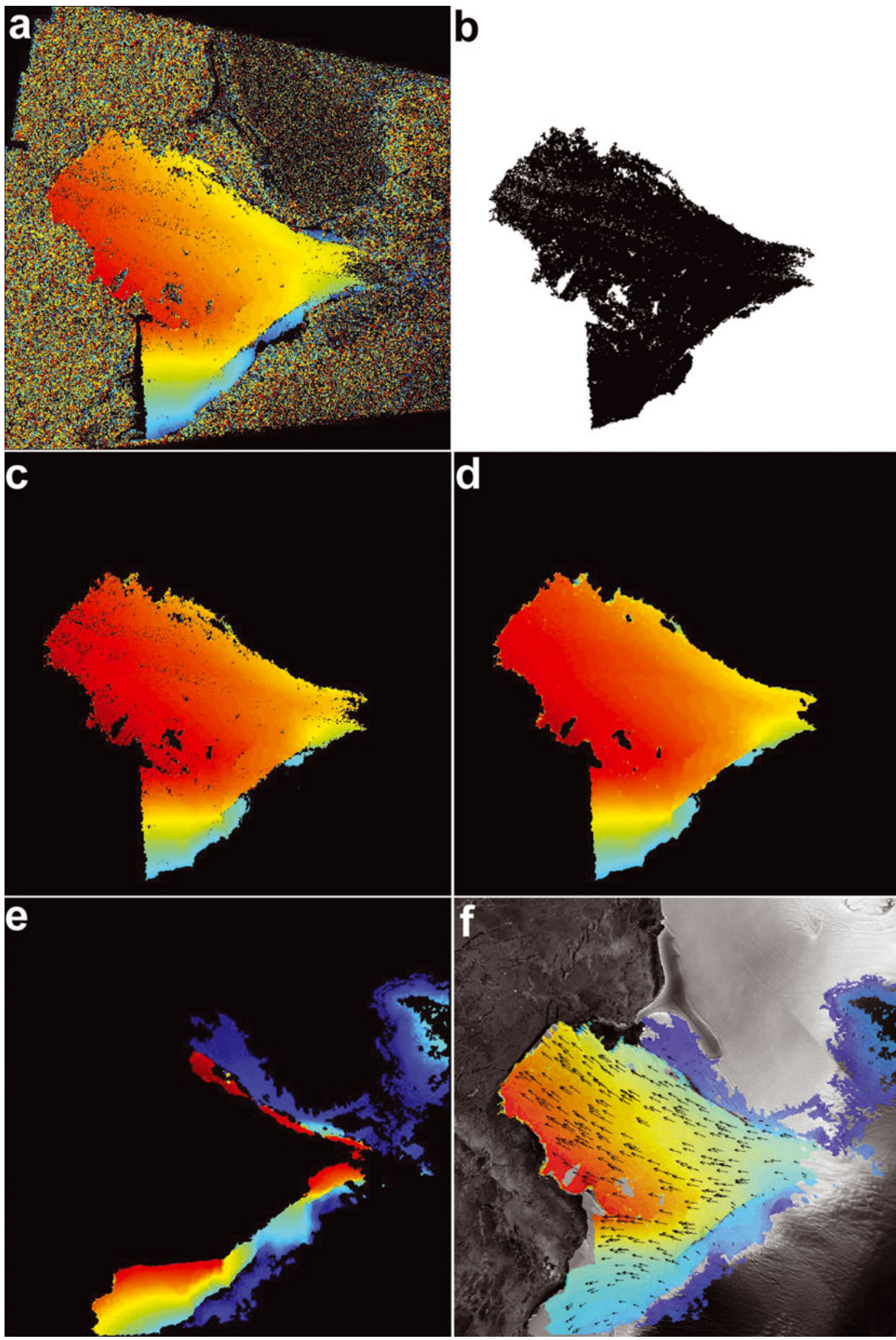

Fig. 1. Ice-flow velocity on the BIS and SWIT. (a) Unfiltered IMCORR output of fast flow; (b) mask created by a region-growing technique; (c) output after the mask is applied; (d) output after leftover outliers are filtered out and small gaps are filled in using an inverse distanceweighted standard deviation filter; (e) filtered output of slow flow; and ( $\mathrm{f}$ ) merged fast and slow velocity field projected on a RADARSAT-1 image with some vectors displayed.

To optimize the derivation of valid velocity data points from the SAR imagery, we extend the feature-tracking approach in several ways (Wuite, 2006). First, we preprocess the imagery using an adaptive neighborhood filter, based on a method described by Rangayyan and others (1998). This reduces noise and results in more successful correlations. Second, we incorporate a variable window extraction routine, so as to improve results in areas where no valid matches are found for smaller search windows. Third, we apply a validation and filtering technique on the output data, based on a region-growing technique and an inverse distance-weighted standard deviation filter (Fig. 1). This 


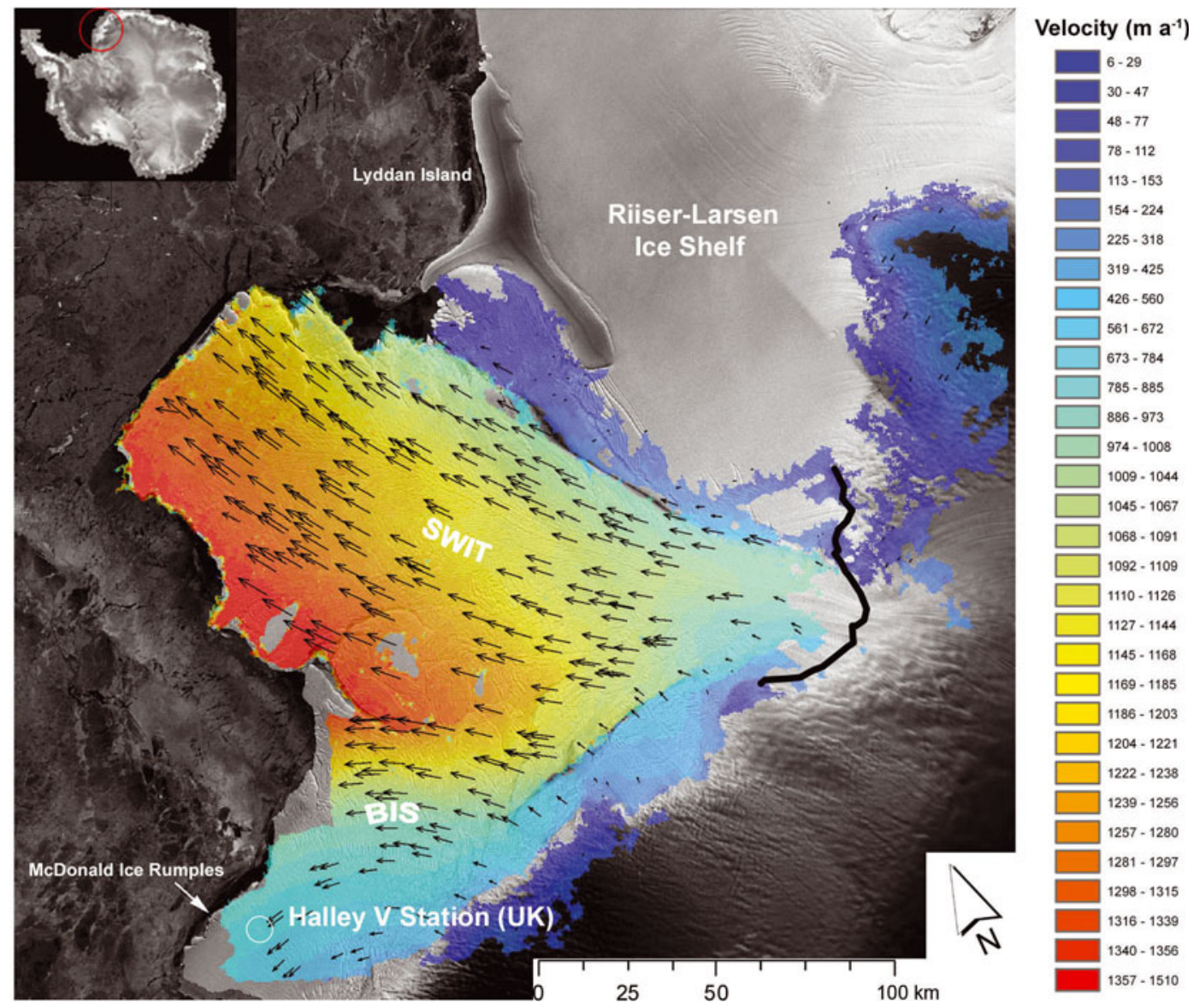

Fig. 2. Ice-flow velocity on the BIS and SWIT on the Caird Coast, East Antarctica (see inset). The velocity field is derived using featuretracking techniques on RADARSAT-1 images of 1997 and 2000 and represents a 3 year average. The map is compiled of more than 200000 velocity data points with a pixel size of $400 \mathrm{~m}$. Vectors show the direction of flow. Vector density has been decimated for display purposes. The solid black line gives the approximate position of SWIT grounding line (adapted from Rignot, 2002). Maximum velocities of $1350 \mathrm{~m} \mathrm{a}{ }^{-1}$ are found in the northwest corner of the ice tongue.

method eliminates invalid data points and fills small data gaps, resulting in a more complete and consistent velocity field. To capture the wide range of velocity in the scene, a large search window is necessary, increasing computation time considerably. To avoid this, we run feature tracking twice with different search window offsets and merge the resulting data.

\section{VELOCITY}

Figure 2 shows 3 year averaged feature-tracking velocity and vectors on the ice shelf. Successful velocity estimates are largely restricted to the area below the grounding line where clear features (crevasses and rifts) are abundant. Upstream of the grounding line, results are poor due to a lack of traceable features. Nevertheless, the velocity map encompasses more then 200000 velocity data points, with a $400 \mathrm{~m}$ pixel size, and gives a detailed view of the velocity field.

We measure a velocity of $720 \pm 35 \mathrm{ma}^{-1}$ for Halley $\mathrm{V}$ station, which agrees well with an earlier reported value of approximately $750 \mathrm{~m} \mathrm{a}^{-1}$ for that period (BAS, 2007). Our data seem to confirm the apparent constant velocity observed between 1972 and 1999. We do not find any evidence of the reported $40 \mathrm{ma}^{-1}$ deceleration, which is not surprising because it started after 1999 (British Antarctic Survey, 2007).

We measure velocities between 850 and $950 \mathrm{ma}^{-1}$ on SWIT about $10 \mathrm{~km}$ downstream of the grounding line, which agrees with values reported in Rignot (2002) and Hulbe and others (2005). Velocity increases significantly downstream of the grounding line, but the velocity structure on the ice tongue is asymmetric. We find velocities up to $1350 \mathrm{~m} \mathrm{a}^{-1}$ on the northwest corner of the ice shelf, while the northeast corner shows maximum values of up to $1200 \mathrm{~m} \mathrm{a}^{-1}$.

\section{RELICT FLOW STRIPES}

The RADARSAT images of the BIS and SWIT reveal marked curvilinear stripes and crevasse bands, some of which are more then $200 \mathrm{~km}$ long. Similar features have been found and studied on the Ross Ice Shelf (Casassa and others, 1991; Fahnestock and others, 2000; Hulbe and Fahnestock, 2007) and the Filchner-Ronne Ice Shelf (Crabtree and Doake, 1980; Swithinbank and others, 1988). These features are not flowlines, which are imaginary lines tangent to the local velocity vector, but flow stripes (also referred to as streak lines). The exact mechanism that produces the stripes is unclear, but it is commonly thought that they represent relict flowlines and are associated with subtle topography (Casassa and others, 1991). A flow stripe can be thought of as the line that a fixed marker placed on the ice would leave on the moving ice, and analysis of these relict flow features can reveal past ice-stream fluctuations when compared with present-day flowlines (MacAyeal and others, 1988; Casassa and others, 1991). In a steady-state system the flow features 

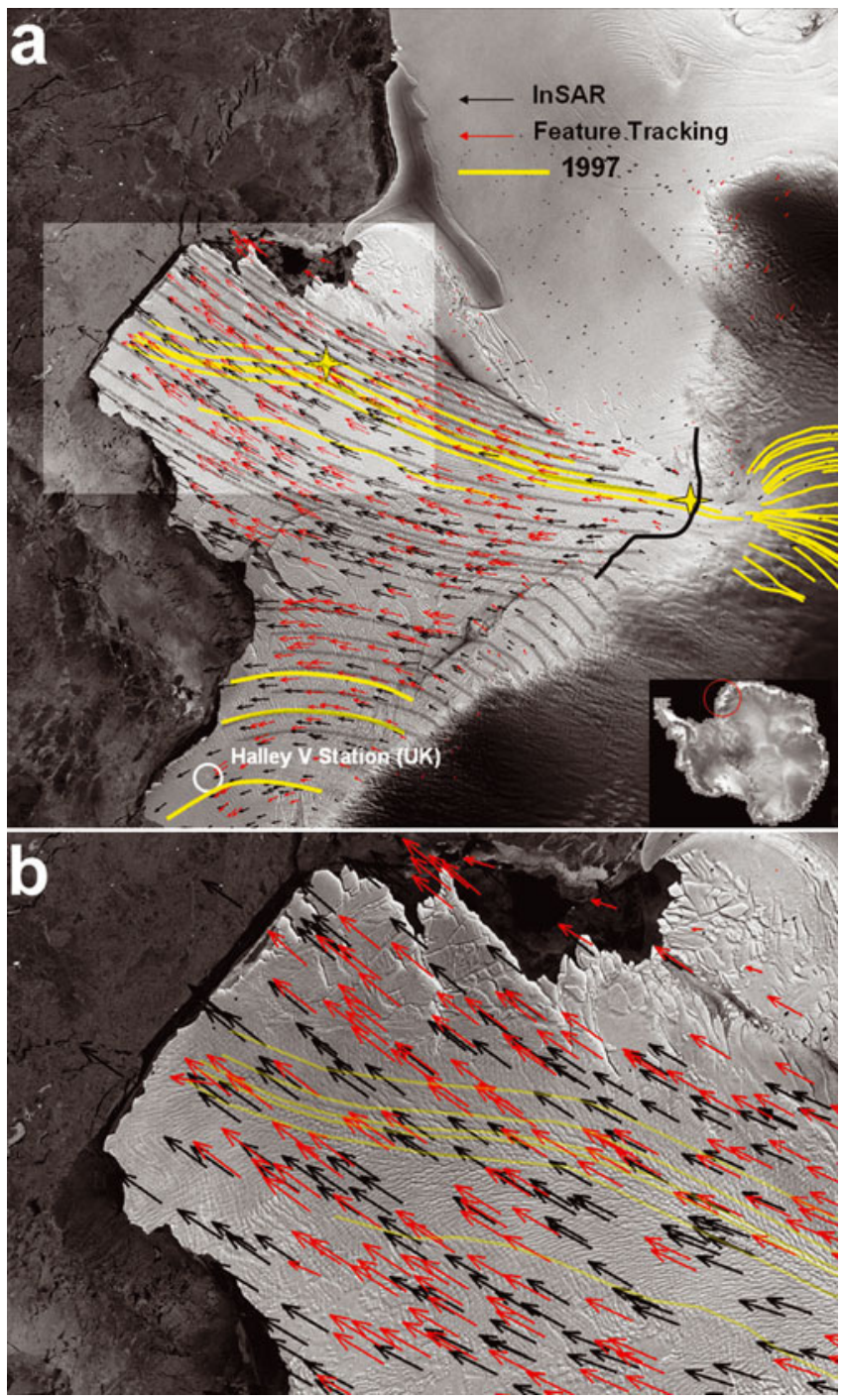

Fig. 3. (a) RADARSAT image of the BIS and SWIT, showing flowlines inferred from the velocity field (grey), traced flow stripes (yellow), feature tracking (red) and InSAR (black) velocity vectors. The solid black line indicates the approximate location of the grounding line (adapted from Rignot, 2002). Stars mark the beginning and end of the velocity profile that is used to estimate the timing of the perturbation. Highlighted square shows area of enlargement in (b). (b) Close-up of the front of SWIT showing clearly the divergence between relict flow stripes and current velocity vectors.

would eventually line up with contemporary flowlines (Fahnestock and others, 2000). Investigations of relict flow stripes can thus reveal glacial events in the past and place present-day fluctuations in context.

In an effort to study the history of the ice shelf, we traced several relict flow stripes on the BIS and SWIT. The yellow lines in Figure 3a mark the stripes and show feature tracking (red) and MAMM InSAR velocity vectors (black) (Jezek and others, 2003) on a 1997 RADARSAT image. The grey lines show the contemporary flowlines and are derived from the velocity vectors. Closer investigation reveals a pronounced divergence between the flow stripes and the contemporary flowlines near the front of SWIT (Fig. 3b). This disparity may indicate a change of flow conditions in the past. On the BIS, near Halley $\mathrm{V}$ station, we observe that the flow stripes make a very sharp bend to the west. Here the stripes run nearly parallel to modern-day flowlines. The pronounced curving of the stripes is likely caused by shallow seabed topography around the McDonald Ice Rumples. Small deviations do exist, perhaps as a result of variable flow in recent decades, but they are not nearly as distinct as on SWIT.

On SWIT the alignment between the current flowlines and the relict flow stripes is reasonably good from the point where the stripes become visible, close to the grounding line, and along the first section of the ice tongue. This suggests that, during the time represented by this distance, flow has been more or less in steady state. We therefore assume that the present-day velocity field can be used to estimate the timing of perturbation. This assumption is supported by MacAyeal and Barcilon (1988) who showed that when an ice-stream fluctuation, occurs two trajectories can be distinguished. The first involves a perturbation at the grounding-line velocity which is transmitted instantaneously to all points downstream. The second develops from a thickness change at the grounding line, which, in contrast to the first case, propagates much slower downstream. The approximate timing of perturbation can be calculated by integrating the product of distance and inverse velocity along the section of a flow stripe that is well aligned with contemporary flow. Since velocity, $V$, can be defined as:

$$
V=\frac{\mathrm{d} x}{\mathrm{~d} t}
$$

the time passed since the fluctuation can be estimated according to:

$$
T=\int_{0}^{\chi} \frac{\mathrm{d} x}{v(i)}
$$

where $T$ is the time it takes for a particle to travel from the flow-stripe initiation point to the spot where the relict flow stripe diverges from the present flow direction $(\chi)$. Taking a velocity profile along a flow stripe from the initiation point to the location of divergence (marked with stars in Fig. 3a), we estimate the timing by plotting distance, $x$, against $v^{-1}$ and calculating the area under the curve from:

$$
T=\sum\left[\frac{v_{i}^{-1}+v_{(i-1)}^{-1}}{2}\left(x_{i}-x_{(i-1)}\right)\right] \text {. }
$$

Using this approach we find $T \approx 137$ years. This value could be less if the grounding-line position has retreated over time.

\section{FLOW-STRIPE RECONSTRUCTION}

To find out what kind of glacial event is recorded by the bending of the stripes, we investigate flow-stripe migration over time by tracing two relict flow stripes identifiable on both 1997 and 2000 RADARSAT images and also on a coregistered 1986 Landsat image. Assuming relative constant flow during the period 1986-2000, we estimate the configuration of the 1997 flow stripes in 2000 and 1986 by extrapolating the position of each point along the line using the derived velocity field.

Figure 4 shows a comparison between the extrapolated flow stripes and the actual position of the stripes visible in the image. Based on the MacAyeal and Barcilon (1988) theory, we believe that the good agreement indicates relatively constant flow since 1986 and justifies further extrapolation in the past to find the possible configuration during the time of perturbation. Using the same flow stripes and assuming steady flow since the perturbation occurred, we estimate their approximate configuration during the time 

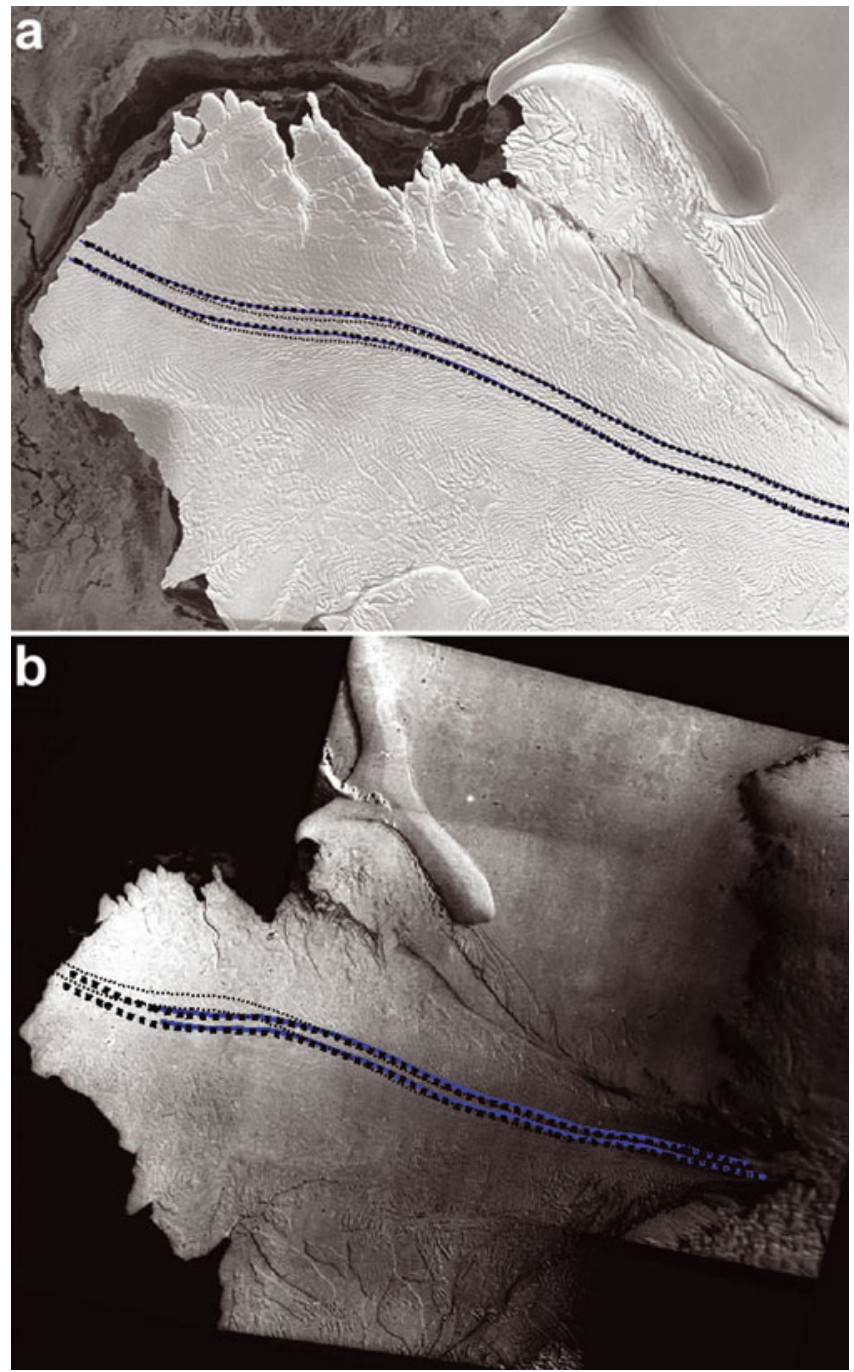

Fig. 4. Comparison between extrapolated relict flow stripes (thick dotted line) and actual position of the same flowlines (blue) on (a) a 2000 RADARSAT image and (b) a 1986 Landsat image. The thin dotted line gives the 1997 position of the same flow stripes. The good agreement indicates that flow has been relatively constant since 1986.

of the flow fluctuation (Fig. 5). The figure shows that at that time the flow stripes were bent sharply towards the west. As is to be expected, the subsequent creep of the ice shelf stretched the markings over time and changed their original configuration.

\section{DISCUSSION}

There are several scenarios to account for the behavior of the flow stripes. It can indicate a more westerly flow of SWIT in the past. Perhaps ice from the western part of the RiiserLarsen Ice Shelf found an outlet west of Lyddan Island blocking SWIT. A subsequent surge of SWIT could have blocked this outlet. We did not find any evidence, in the form of flow-stripe patterns or otherwise, to indicate that the Riiser-Larsen Ice Shelf has undergone such a major change, and the scenario seems unlikely considering the thickness and high surface slope necessary to force much ice through the gap. Another option is that SWIT was less coupled to its eastern margin in the past, allowing the ice to flow more towards the west. However, at present there appears to be

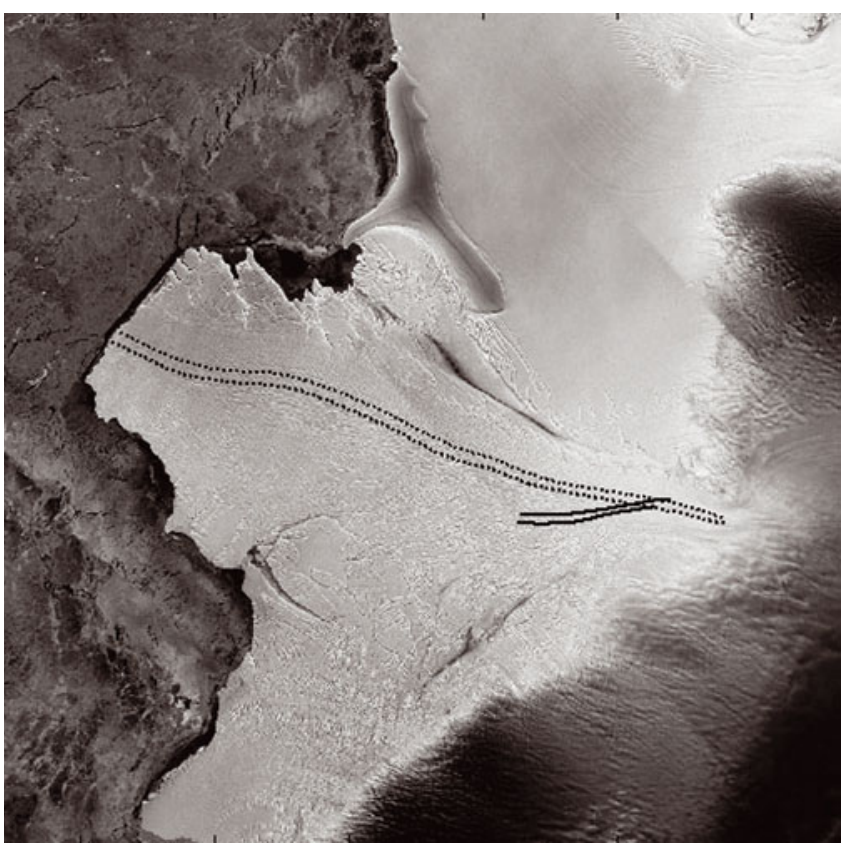

Fig. 5. Reconstructed configuration of two relict flow stripes at the approximate time of perturbation (solid lines), 137 years earlier, and position of the stripes on a 1997 image (dotted line). The extrapolation makes use of the derived velocity field (Fig. 2) to estimate the configuration in the past. The reconstruction indicates that flow-stripe bending was more extreme in the past and has since stretched out as a result of velocity gradients along the ice tongue.

hardly any coupling between SWIT and the ice on its eastern flank, as indicated by the distinct velocity step along the margin, which renders this scenario implausible as well.

Alternatively, assuming the flowlines have remained virtually unchanged with time, the initiation point of the stripes might have shifted over time. This suggests a change in dynamics perhaps due to thinning and an associated shift of the grounding-line position. A similar model is described by Jezek (1984) to explain a series of debris tracks from Crary Ice Rise crossing present-day flowlines on the Ross Ice Shelf.

Earlier observations by E. Shackleton's expedition seem to support this hypothesis. During Shackleton's expedition of $1914 / 15$ he made a map of the ice front of SWIT, which showed a large promontory in the Weddell Sea that has since calved off (Thomas, 1973). Perhaps there was less fast ice to cement the tongue around the flanks. Although we have no direct evidence, it would be plausible to assume that the ice tongue was thicker as well at that time and the grounding line more advanced. The Lyddan Island Ice Rise would, as it does today, limit the eastern flank of SWIT and force a more westerly flow. A subsequent thinning could have led to decoupling from the bed and a simpler more easterly flow, although a flow direction change is not required to explain the bending of the flow stripes.

BEDMAP sea-floor topography (Lythe and others 2000) shows that the bottom topography west of Lyddan Island is reasonably flat and very shallow (250-350 m). Using Ice, Cloud and land Elevation Satellite (ICESat)-derived icethickness estimates we find that even today most of the ice on the east flank of SWIT must be nearly grounded. A slightly thicker ice tongue must have run aground and perhaps favored a more easterly flow, as suggested by the relict flow stripes. 
The hypothesis is further supported by the difference between the crevasse pattern of the ice in the northeast corner of SWIT and the rest of the ice tongue (visible in Fig. 3b). This area lacks the fine structure found elsewhere and seems to consist of larger rafts fastened by marine ice, suggesting a different flow regime or source for this part of the ice tongue. In appearance it resembles closely the ice currently attached in the Lyddan Island embayment just south of it. The flowlines on this part of the ice tongue originate at the present-day eastern shear margin. It seems therefore plausible that in the past this section was grounded, effectively blocking flow, and has recently become ungrounded and detached.

\section{CONCLUSIONS}

We present 3 year averaged feature-tracking velocities of the BIS and SWIT. The high-resolution two-dimensional surface velocity map can serve as a benchmark for gauging possible (future) changes in velocity and dynamics. We observe a pronounced divergence between relict flow stripes and current flowlines. The good agreement between extrapolated 1997 flowlines and their actual position on the 1986 Landsat image shows that the stripes are in fact old relict flowlines. A comparison between present-day flowlines, derived from the velocity field, and relict flow stripes on the ice tongue shows that a regime change occurred on the ice tongue in the past. Assuming relatively constant flow since the event occurred, we estimate the timing of the event to be less than 140 years ago. The pattern of relict flow stripes suggests recent ungrounding associated with grounding-line retreat of SWIT and subsequent ice thinning, which seems to be supported by historical observations and bottom topography.

\section{ACKNOWLEDGEMENTS}

This work was supported by a grant from NASA's Polar Oceans and Ice Sheets Program and by NASA Headquarters under the Earth System Science Fellowship Grant NGT530533.

\section{REFERENCES}

Ardus, D.A. 1965. Surface deformation, absolute movement and mass balance of the Brunt Ice Shelf near Halley Bay, 1961. Br. Antarct. Surv. Bull. 6, 21-41.

Berthier, E., B.H. Raup and T.A. Scambos. 2003. New velocity map and mass-balance estimate of Mertz Glacier, East Antarctica, derived from Landsat sequential imagery. J. Glaciol., 49(167), 503-511.

Bindschadler, R.A. and T.A. Scambos. 1991. Satellite-imagederived velocity field of an Antarctic ice stream. Science, 252(5003), 242-246.

Bindschadler, R., P. Vornberger, D. Blankenship, T. Scambos and R. Jacobel. 1996. Surface velocity and mass balance of Ice Streams D and E, West Antarctica. J. Glaciol., 42(142), 461-475.
British Antarctic Survey (BAS). 2007. Proposed construction and operation of Halley VI Research Station, and demolition and removal of Halley $V$ Research Station, Brunt Ice Shelf, Antarctica. Final comprehensive environmental evaluation, March 2007. Cambridge, British Antarctic Survey.

Casassa, G., K.C. Jezek, J. Turner and I.M. Whillans. 1991. Relict flow stripes on the Ross Ice Shelf. Ann. Glaciol., 15, 132-138.

Crabtree, R.D. and C.S.M. Doake. 1980. Flow lines on Antarctic ice shelves. Polar Rec., 20(124), 31-37

Fahnestock, M.A., T.A. Scambos, R.A. Bindschadler and G. Kvaran. 2000. A millennium of variable ice flow recorded by the Ross Ice Shelf, Antarctica. J. Glaciol., 46(155), 652-664.

Hulbe, C. and M. Fahnestock. 2007. Century-scale discharge stagnation and reactivation of the Ross ice streams, West Antarctica. J. Geophys. Res., 112(F3), F03S27. (10.1029/ 2006JF000603.)

Hulbe, C.L., R. Johnston, I. Joughin and T. Scambos. 2005. Marine ice modification of fringing ice shelf flow. Arct. Antarct. Alp. Res., 37(3), 323-330.

Jezek, K.C. 1984. Recent changes in the dynamic condition of the Ross Ice Shelf, Antarctica. J. Geophys. Res., 89(B1), 409-416.

Jezek, K.C., ed. 1998. RADARSAT Antarctic mapping project. Proceedings of the Post Antarctic Imaging Campaign-1 Working Group Meeting, 18 November 1997, Columbus, Ohio. Byrd Polar Res. Cent. Rep. 17.

Jezek, K.C. 2002. RADARSAT-1 Antarctic Mapping Project: changedetection and surface velocity campaign. Ann. Glaciol., 34, 263-268.

Jezek, K.C., K. Farness, R. Carande, X. Wu and N. Labelle-Hamer. 2003. RADARSAT 1 synthetic aperture radar observations of Antarctica: Modified Antarctic Mapping Mission, 2000. Radio Sci., 38(4), 8067. (10.1029/2002RS002643).

Lucchitta, B.K., K.F. Mullins, A.L. Allison and J.G. Ferrigno. 1993. Antarctic glacier-tongue velocities from Landsat images: first results. Ann. Glaciol., 17, 356-366.

Lythe, M.B., D.G. Vaughan and BEDMAP consortium. 2000. BEDMAP - bed topography of the Antarctic. (Scale 1 : 10000 000.) Cambridge, British Antarctic Survey. (BAS (Misc) 9.)

MacAyeal, D.R. and V. Barcilon. 1988. Ice-shelf response to icestream discharge fluctuations: I. Unconfined ice tongues. J. Glaciol., 34(116), 121-127.

MacAyeal, D.R., R.A. Bindschadler, K.C. Jezek and S. Shabtaie. 1988. Can relict crevasse plumes on Antarctic ice shelves reveal a history of ice-stream fluctuation? Ann. Glaciol., 11, 77-82.

Rangayyan, R.M., M. Ciuc and F. Faghih. 1998. Adaptiveneighborhood filtering of images corrupted by signal-dependent noise. Appl. Opt., 37(20), 4477-4487.

Rignot, E. 2002. Mass balance of East Antarctic glaciers and ice shelves from satellite data. Ann. Glaciol., 34, 217-227.

Simmons, D.A. and J.R. Rouse. 1984. Accelerating flow of the Brunt Ice Shelf, Antarctica. J. Glaciol., 30(106), 377-380.

Swithinbank, C., K. Brunk and J. Sievers. 1988. A glaciological map of Filchner-Ronne Ice Shelf, Antarctica. Ann. Glaciol., 11, 150155.

Thomas, R.H. 1973. The dynamics of the Brunt Ice Shelf, Coats Land, Antarctica. Br. Antarct. Surv. Sci. Rep. 79.

Wuite, J. 2006. Spatial and temporal dynamics of three East Antarctic outlet glaciers and their floating ice tongues. (PhD thesis, The Ohio State University.) 